\title{
Oral Health of Tobacco and Non-Tobacco Consumers Inyaounde, Cameroon
}

\author{
Ashu Michael Agbor and Yougang Francine Josepha Jupkwo
}

\section{ABSTRACT}

Introduction: Tobacco consumption is risk factor of many infectious and endemic diseases. The objective of our study was to compare the oral health of smokers and non-smokers in the city of Yaoundé, Cameroon.

Methodology: This was a cross-sectional descriptive study using a stratified random sampling that took place between April to September 2014 in which both smokers and non-smokers participated.

Results: Two hundred smokers and 200 non-smokers comprising 341 men and 59 women participated in the study with the 25-35 years age group was most represented. A third of the smokers were unemployed $72(36.0 \%), 45(22.5 \%)$ had low income employment, 94(51.4\%) were initiated into smoking when they were less than 10 years old; 90(45.5\%) took between 1 and 15 sticks of cigarettes a day. Supra-gingival calculus, halitosis, xerostomia, periodontal diseases, tooth mobility, painless carious cavitation's and tooth loss were more frequent in smokers. Toothache from carious cavitations, tooth loss was more frequent in smokers while toothache from deep caries was found more in non-smokers.

Conclusion: The frequency of oral diseases was higher in tobacco smokers than non-smokers. People from low socioeconomic status, males and the unemployed were mostly affected.

Recommendations: The government and stakeholders in public health should formulate policies that will reduce cigarette smoking and also involve oral health workers in their campaigns.

Key words: Tobacco, oral health, smokers, non-smokers, Cameroon
Published Online: April 09,2020

ISSN: $2684-4443$

DOI : 10.24018/ejdent.2020.1.2.3

Ashu Michael Agbor,

Faculty of Dentistry, Université des

Montagnes, Cameroon

(agborasm@gmail.com )

*Corresponding Author

Yougang Francine Josepha Jupkwo,

Faculty of Dentistry,

Université des Montagnes

Cameroon

( lafrancinez@yahoo.com )

\section{INTRODUCTION}

Among some of the diseases that affect people in developing countries is tobacco related diseases that are major causative risk factors of many infectious and endemic diseases. Smoking has been identified as the primary cause of avoidable deaths in developing countries [1, 2, 3, 4]. Cigarettes or smokeless tobacco have been reported to have direct or indirect toxic effects on practically every organ of the body presenting as a significant risk factor for cardiovascular, and respiratory diseases [4]. There is no smoking without risk; however, stopping smoking at any age is beneficial [4].

Tobacco consumption has also been associated with many socio-economic and political problems. Approximately 1.1 billion people around the world smoke. It has been projected that between 2014 and the year 2025, this number will most likely increase to 1.6 billion. By 2030, 10 million tobaccorelated deaths will have occurred, and is assumed that most deaths will be concentrated in developing countries [5]. Tobacco costs more than half a trillion dollars in economic damages annually $[6,7,8]$ and kills more than 5 million people per year. Tobacco is estimated to kill up to one of every two users. It is responsible for 1 in 10 adult deaths.
Among the five greatest risk factors for mortality, it is the single most preventable cause of death [7].

As the use of tobacco declined in high-income countries, the tobacco industry has increasingly turned to low and middle income countries, particularly to Africa, Asia, and Eastern Europe to recruit new users [6]. The epidemic and the growing smoking crisis in Africa is a menace to the health of the continent with significant socio-economic repercussions anticipated in the coming years [2].

According to the 2013 World Report on Tobacco Consumption, Cameroon has more than one million active adult smokers and 66,000 Cameroonians die of the effects of tobacco every year [7]. Furthermore, the World Bank has reported that the prevalence of tobacco smoking among adult males in Cameroon increased from $29 \%$ in 2010 to $34 \%$ in 2012 [7].

The tobacco epidemic is a multidisciplinary scourge that interests all medical specialties and the oral cavity is one of the first organs of the body where the symptoms of tobacco toxicity manifest primarily in the oral hard and soft tissue. The adverse effects of smoking include periodontal diseases and dental caries which are the most prevalent oral diseases and are also the primary causes of tooth loss [8]. Poor oral 
health could adversely influence individuals' overall quality of life, self-esteem and confidence because of the poor appearance of teeth, the presence of bad breath and pain associated with these diseases of the oro-facial region $[8,9]$.

Alcohol-associated smoking is responsible for $70 \%$ of oral cancers and $90 \%$ of cancers of the head and neck [10] with one in two smokers likely to lose their teeth [10]. Addicted patients generally present with a neglected oral environment accumulated with pathology, poor hygiene, deteriorated dental conditions and financial difficulties $[10,11,12,13]$.

It has been shown that half of all periodontal diseases are caused by smoking, and that their prevalence decreases after cessation of smoking [12, 14-19]. Gonsalves et al. (2007) identified oral diseases such as candidiasis, lichen planus, smoker melanoses, necrotic ulcerative gingivitis, gingival hyperplasia, leukoplakia, erytroplakias, neoplasia, periodontitis, tooth discolorations, dental-maxillary deformities, chronic ulcerations, osteolysis and oral cancer to be associated with smoking [16].

In Africa, there is a paucity of information on the impact of tobacco on the oral health. Agbor et al. [2013] reported the impact of smokeless tobacco on the oral cavity in Cameroon and identified oral precancerous lesions among adult consumers of smokeless tobacco in a rural setting in the Western region of Cameroon [14]. The dearth in information on the impact of tobacco on the oral health necessitated this study in an urban setting of Cameroon. The objective of the study was to compare the prevalence of dental pathologies among smokers and non-smokers in Yaoundé in the Cameroon.

\section{METHODOLOGY}

This was a cross sectional descriptive study using a convenience sampling that took place between April to September 2014 in which both smokers and non-smokers participated.

The study was carried out in Yaoundé, the political capital of Cameroon, a city with a population of 2440462 inhabitants (2011); after Douala in Cameroon, it is the second city largest city of the Central African Sub-Region.

For the present study, the map of Yaoundé was into 5 equal zones. In each zone, volunteers were randomly recruited until smokers and non smokers were up to 200 per group. Participants were selected from houses, residential areas, streets and supermarkets. Participants were given appointments in selected dental offices at each of the selected zones for an intra-oral clinical examination carried out by dentists who were trained and calibrated for this study.

The participants were given self-administered questionnaires with closed and open-ended questions to complete. After completion of the questionnaires, an intra-oral examination was performed..

The questionnaire was used to collect data defining the sociodemographic characteristics of the participants such as age, sex, profession, marital status etc. The second part of the questionnaire was used to collect information on the socioeconomic status of the participants using the National socioeconomic classification of Statistics (NS-SEC). The NS-SEC is a public health and social science tool that assigns social classes according to occupational titles and responsibilities over the work force. It distinguishes between the employers, employees and the unemployed [20]. The last part of the questionnaire collected information on past medical, dental and social history of the participants such as current tobacco consumption status, forms of tobacco consumed, frequency of tooth brushing.

Clinical examinations were carried out under bright natural light and the periodontal status of the participants was assessed using a WHO periodontal probe. The periodontal status and the treatment needs of the participants were described using classification of gingival recessions, dental mobility [21].

The Community Periodontal Index Treatment Needs (CPITN) was used to determine the periodontal status of participants and their corresponding treatment needs. The mouth was divided into six areas (sextants) and a selected tooth from each sextant (tooth number 11,16,26,36,46,31 according palmers nomenclature) were evaluated by assigning a score for each face (distal, buccal, mesiobuccally and lingual). If a tooth to be selected in the sextant is absent and adjacent tooth was selected (Table 1.)

Gingival recession was evaluated using Miller's Index of gingival recessions [22] is as follows:

Class I: Marginal tissue recession not extending to the mucogingival junction (MGJ). No loss of interdental bone or softtissue

Class II: Marginal recession extending to or beyond the MGJ. No loss of interdental bone or soft-tissue

Class III: Marginal tissue recession extends to or beyond the MGJ. Loss of interdental bone or soft-tissue is apical to the CEJ, but coronal to the apical extent of the marginal tissue recession

Class IV: Marginal tissue recession extends to or beyond the MGJ. Loss of interdental bone extends to a level apical to the extent of the marginal tissue recession.

Tooth mobility was evaluated using Miller's Index of tooth mobility which assesses the degree of tooth mobility by assigning a score per tooth as follows:

Class 0: $0-0.2 \mathrm{~mm}$. Physiological Mobility, distinctive between two fingers;

Class 1: $<1 \mathrm{~mm}$ (Horizontal)

Class 2: $>1 \mathrm{~mm}$ (Horizontal) Cross Mobility $>1 \mathrm{~mm}$;

Class 3: > $1 \mathrm{~mm}$ (Horizontal+vertical mobility)

\section{A. Analysis of data}

The data obtained were analysed using SPSS Version 17 software. The statistical test used was the $\mathrm{Chi}^{2}$ with the significance level of $\mathrm{p} \leq 0.05$. 


\section{B. Ethics}

Ethical Clearance was obtained from the Institutional Research Review board, Research and ethics committee) of the Université des Montagnes-Bangante. Informed consent was obtained from each participant. Our study was conducted in strict observance of medical confidentiality and without financial participation of the subjects. The participants were informed that they could at any time discontinue participation in the study without any prior warning, without any questions being asked and it not affecting their care.

\section{RESULTS}

A. Socio-demographic characteristics

Four hundred participants were recruited in the present study consisting of 200 smokers and 200 non-smokers; 341 (85.2\%) men and $59(14.8 \%)$ women; with a male to female sex ratio of 5:7. Smokers comprised $13(6.5 \%)$ of women and 187 $(93.5 \%)$ men; $46(23 \%)$ of non-smokers were women and 154 (77\%) men.

The mean age of the entire population was 34.8 years (women 31.3 years and men 35.4 years). The mean age of smokers was $36.24 \pm 13$ years (females $35.5 \pm 16.5$ years; males $36.29 \pm 12$ years). The most representative age group of smokers was that of 25-35 years age group which was made up $40.5 \%$ of the sample. (Table 1 ).

TABLE 1. AGE OF FIRST INITIATION INTO SMOKING

\begin{tabular}{|l|l|l|}
\hline Age of initiation (years) & Frequency (n) & Percentage (\%) \\
\hline $0-10$ & 94 & 51 \\
\hline $11-20$ & 60 & 32.8 \\
\hline $21-30$ & 24 & 13.1 \\
\hline $31-40$ & 13 & 7.1 \\
\hline$>40$ & 9 & 4.9 \\
\hline
\end{tabular}

More than a third of the unemployed $72(36 \%)$ were the most affected by tobacco smoking followed by people from the common occupation age groups $45(22.5 \%)$. There was low tobacco consumption among professionals of group 1 and 2 or people of high socioeconomic status which constitute the managers and high and professionals (Table 2).

TABLE 2. DISTRIBUTION OF PARTICIPANTS BY PROFESSIONAL

\begin{tabular}{|c|c|c|}
\hline \multicolumn{3}{|c|}{ CATEGORY } \\
\hline Profession & Non-smokers n(\%) & Smokers n(\%) \\
\hline $\begin{array}{l}\text { Managers and high } \\
\text { professionals }\end{array}$ & $2(1.0)$ & $2(1)$ \\
\hline $\begin{array}{l}\text { Managers and lower } \\
\text { professionals } \\
\text { Engineers, Teachers) }\end{array}$ & $1(0.5)$ & $3(1.5)$ \\
\hline $\begin{array}{l}\text { Intermediate occupations } \\
\text { (lawyers, Contract, } \\
\text { Secretaries) }\end{array}$ & $3(1.5)$ & $10(5.0)$ \\
\hline $\begin{array}{l}\text { Small businesses and self- } \\
\text { employed (Restorers, } \\
\text { Retailers) }\end{array}$ & $16(8.0)$ & $17(8.5)$ \\
\hline $\begin{array}{lr}\text { Supervisory } & \text { and lower } \\
\text { technical } & \text { (Building } \\
\text { Technicians) } & \\
\end{array}$ & $27(13.5)$ & $13(6.5)$ \\
\hline $\begin{array}{l}\text { Semi-routine occupations } \\
\text { (Hairdressers, Drivers) }\end{array}$ & $22(11.0)$ & $38(19.0)$ \\
\hline $\begin{array}{l}\text { Common Occupations } \\
\text { (Students, housewives) }\end{array}$ & $29(14.5)$ & $45(22.5)$ \\
\hline $\begin{array}{l}\text { Never worked and long- } \\
\text { term unemployed }\end{array}$ & $100(50.0)$ & $72(36.0)$ \\
\hline Total & $200(100.0)$ & $200(100,00)$ \\
\hline
\end{tabular}

\section{B. The use of tobacco.}

More than half 94 (51.4\%) of the smokers had had their first contact with tobacco when they were less than 10 years old, $60(32 \%)$ between the ages of $11-20,24(13.1 \%)$ between the ages of $21-30,13(7.1 \%)$ between $31-40$ years, while very few smoker $9(4.5 \%)$ were initiated when above 40 years old (Table 3).

TABLE 3. AGE OF FIRST INITIATION INTO SMOKING

\begin{tabular}{|l|l|l|}
\hline Age of initiation (years) & Frequency (n) & Percentage (\%) \\
\hline $0-10$ & 94 & 51 \\
\hline $11-20$ & 60 & 32.8 \\
\hline $21-30$ & 24 & 13.1 \\
\hline $31-40$ & 13 & 7.1 \\
\hline$>40$ & 9 & 4.9 \\
\hline
\end{tabular}

\section{Tobacco consumption}

More than half of 104 (52.0\%) of the participants were strictly consumed tobacco only. Among the non-smokers, 63 (31.5\%) consume alcohol and $125(62.5 \%)$ do not consume any narcotic. Three quarters $143(82.7 \%)$ of the smokers reported consuming alcohol and smoking tobacco, 21 $(12.1 \%)$ used tobacco in combination with other narcotics like cannabis, heroine or cocaine, and $2(1.2 \%)$ combine tobacco and tramadol.

\section{Forms of tobacco used}

The majority $182(95.3 \%)$ of the participants consumed pure tobacco, while $5(2.6 \%)$ cigars, $2(1.0 \%)$ pipe and $3(12.0 \%)$ consume electronic cigarettes. Almost half 90 (45.5\%) of smokers take between 1 and 15 sticks of cigarettes a day, 66 (33.5\%) between 16 and 30 sticks and 4(2.0\%) about 31-80 sticks of cigarettes a day (Table 4).

TABLE 4: NUMBER OF CIGARETTES CONSUMED PER DAY
\begin{tabular}{|l|l|}
\hline Number of cigarettes consumed per day & N(\%) \\
\hline $1-15$ Sticks & $90(45.5)$ \\
\hline $16-30$ Sticks & $66(33.5)$ \\
\hline $31-50$ Sticks & $24(12.1)$ \\
\hline $51-70$ Sticks & $9(4.6)$ \\
\hline $71-99$ Sticks & $4(2.0)$ \\
\hline Total & $193(97.7)$ \\
\hline
\end{tabular}

\section{E. Practice of oral hygiene}

Almost all 191 (95.5\%) the non-smokers and four-fifth 168 (84) of smoker use toothbrushes; 175 Oral hygiene Practices. The majority $(87.5 \%)$ non-smokers and 148 (80.4\%) smokers use toothpastes and 25 (12.5\%) smokers do not brush their teeth. Three-quarters of the 148 (74.4\%) nonsmokers and half of $106(53 \%)$ of smokers brush their teeth in the morning (Table 5). 
TABLE 5: ORAL HEALTH PRACTICE

\begin{tabular}{|l|c|c|}
\hline Oral health practice & $\begin{array}{l}\text { Non-smokers } \\
\text { n(\%) }\end{array}$ & $\begin{array}{l}\text { Smokers } \\
\mathbf{n ( \% )}\end{array}$ \\
\hline Toothbrushes & $191(95.5)$ & $168(84)$ \\
\hline Toothpastes & $175(87.5)$ & $148(80.4)$ \\
\hline Chewing sticks & $1(0.5)$ & $9(4.5)$ \\
\hline Charcoal/Salt & $13(6.5)$ & $18(9)$ \\
\hline Nothing & $8(4.0)$ & $25(12.5)$ \\
\hline Frequency of daily brushing & \multicolumn{2}{|l}{} \\
\hline Morning only & $148(74.4)$ & $106(53)$ \\
\hline Morning-evening & $58(29)$ & $34(17.1)$ \\
\hline Morning-afternoon-evening & $5(2.5)$ & $4(2)$ \\
\hline No brushing & $13(6.5)$ & $31(15.5)$ \\
\hline Total & $\mathbf{2 0 0 ( 1 0 0 )}$ & $\mathbf{2 0 0}(\mathbf{1 0 0})$ \\
\hline
\end{tabular}

Dental visits was generally poor in both groups and $105(62.1 \%)$ smokers did not visit the clinic; both smoker 56 (33.1\%) and non-smokers 60 (96.8\%) visit the dentist only when there is a problem (Table 5). Reasons for not visiting was lack of money $56(43 \%)$ for smokers, $107(78.1 \%)$ because of no medical problems for non-smokers and 52 (38.5\%) smokers (Table 6).

TABLE 6: ORAL HEALTH SEEKING BEHAVIOR

\begin{tabular}{|l|c|c|}
\hline Visit to the dentist & Non-smokers n(\%) & Smokers n(\%) \\
\hline Once/ month & $2(3.2)$ & $1(0.6)$ \\
\hline Twice / month & $0(0)$ & $7(4,1)$ \\
\hline Twice / year & $0(0)$ & $7(4.1)$ \\
\hline No visits & $0(0) 0$ & $105(62.1)$ \\
\hline If problems only & $60(96.8)$ & $56(33.1)$ \\
\hline Total & $\mathbf{2 0 0 ( 1 0 0 )}$ & $\mathbf{2 0 0 ( 1 0 0 )}$ \\
\hline
\end{tabular}

More than three quarters $169(84.5 \%)$ of smokers and $124(62)$ of non-smokers presented with supra-gingival calculus. Gingival recession was more frequent in smokers than nonsmokers. Second degree mobility $52(26 \%)$ was more frequent among the smokers than the non-smokers (Table 7).

TABLE 7. ORAL HYGIENE STATUS

\begin{tabular}{|l|l|l|l|l|}
\hline \multicolumn{1}{|c|}{ Calculus type } & $\begin{array}{l}\text { Smokers } \\
\text { n(\%) }\end{array}$ & $\begin{array}{l}\text { Non- } \\
\text { smokers } \\
\text { n(\%) }\end{array}$ & $\begin{array}{l}\text { P } \\
\text { value }\end{array}$ & $\begin{array}{l}\text { Risk } \\
\text { ratio }\end{array}$ \\
\hline Sub-gingival calculus & $15(7.5)$ & $76(38.0)$ & 0.000 & 0.28 \\
\hline Supra-gingival calculus & $169(84.5)$ & $124(62.0)$ & & \\
\hline $\begin{array}{l}\text { Degree of calculus } \\
\text { deposits }\end{array}$ & \multicolumn{5}{|l|}{} \\
\hline+ & $5(2.5)$ & $140(70.0)$ & & \\
\hline++ & $24(12.0)$ & $40(20.0)$ & & \\
\hline+++ & $171(85.5)$ & $20(10.0)$ & & \\
\hline $\begin{array}{l}\text { Location and dept of } \\
\text { periodontal pockets }\end{array}$ & & & & \\
\hline $\begin{array}{l}\text { Deep pockets (less than } \\
\text { 6mm) }\end{array}$ & $8(4.0)$ & $2(1.0)$ & 0.4 & \\
\hline $\begin{array}{l}\text { Superficial pockets (4- } \\
\text { 5mm) }\end{array}$ & $12(6.0)$ & $13(6.5)$ & 0.4 & \\
\hline $\begin{array}{l}\text { Pocket from gingival } \\
\text { hyperplasia (2-3mm) }\end{array}$ & $24(12.0)$ & $38(19.0)$ & 0.4 & \\
\hline
\end{tabular}

\begin{tabular}{|l|l|l|l|l|}
\hline Gingival recession & \multicolumn{5}{|l|}{} \\
\hline Class I & $50(25.0)$ & $22(11.0)$ & 0.003 & \\
\hline Class II & $67(33.5)$ & $16(8.0)$ & 0.12 & 1.1 \\
\hline Class III & $18(9.0)$ & $13(6.5)$ & 0.13 & 0.8 \\
\hline Class IV & $30(15.0)$ & $10(5.0)$ & 0.2 & 1.1 \\
\hline Tooth Mobility & & & & \\
\hline Normal & $18(9.0)$ & $80(40.0)$ & 0.5 & 1 \\
\hline $1^{\text {st }}$ degree & $10(5.0)$ & $50(25.0)$ & 0.4 & 0.8 \\
\hline $2^{\text {nd }}$ degree & $52(26.0)$ & $10(5.0)$ & 0.0001 & 4.5 \\
\hline $3^{\text {rd }}$ degree & $20(10.0)$ & $12(6.0)$ & 0.0001 & 3.4 \\
\hline $4^{\text {th }}$ degree & $41(20.5)$ & $6(3.0)$ & 0.0001 & 4.7 \\
\hline
\end{tabular}

\section{F. Caries indices}

Toothache as a result of deep caries $63(31.5 \%)$ was found in non-smokers , 48(29.8\%) smokers; painless carious cavitations as a result of superficial caries $11(5.5 \%)$ in nonsmokers, $72(44.7 \%)$ smokers and tooth mobility $3(1.5 \%)$ in non-smokers , $22(13.7 \%)$ smokers. Half of 74 (48.7\%) of smokers had used indigenous treatments thereby aggravating their dental conditions and $56(36.8 \%)$ lost their teeth avulsions. The smoking population had a very high caries index. The mean DMFT for smokers was four times (13.8) than the mean DMFT for non-smokers above 4.4 (Table 8).

TABLE 8: MEAN DMFT OF SMOKERS AND NON-SMOKERS

\begin{tabular}{|c|c|c|c|c|}
\hline $\begin{array}{l}\text { Caries } \\
\text { index }\end{array}$ & $\begin{array}{l}\text { Non } \\
\text { smokers }\end{array}$ & Smokers & P-value & Risk ratio \\
\hline $\begin{array}{l}\text { Decayed } \\
\text { teeth }\end{array}$ & 567 & 2100 & \multirow[t]{3}{*}{0.00001} & \multirow[t]{3}{*}{1.11} \\
\hline $\begin{array}{l}\text { Missing } \\
\text { teeth }\end{array}$ & 257 & 624 & & \\
\hline $\begin{array}{l}\text { Filled } \\
\text { teeth }\end{array}$ & 72 & 36 & & \\
\hline $\begin{array}{l}\text { Mean } \\
\text { DMFT }\end{array}$ & 4.4 & 13.8 & - & - \\
\hline
\end{tabular}

\section{G. Edentulousness}

Three-quarters (152) of non-smokers and more than twothirds of smokers presented with no tooth loss, while 68 smokers had lost 1-5 teeth; 40 Smokers 6-12 teeth; 10 Smokers $12-17$ and 7 teeth smokers have lost from 18 to 26 teeth. No non-smoker has lost more than 17 teeth. The major history of the population had toothache $63(31.5 \%)$, painless carious cavitations $72(44.7 \%)$, and $22(13.7 \%)$ of tooth mobility. Half of 74 (48.7\%) of smokers suffered indigenous treatments exacerbating their oral condition and $56(36.8 \%)$ had avulsions.

Dry mouth (xerostomia) was experienced by $87(43.7 \%$ ) smokers, $16(8.0 \%)$ non-smokers, $78(39.5 \%)$ smokers presented with periodontal disease while $48(24 \%)$ was found among non-smokers (Table 9). 
TABLE 9. INTRA ORAL PATHOLOGIES

\begin{tabular}{|l|l|l|}
\hline Disease & $\begin{array}{l}\text { Smokers } \\
\text { N(\%) }\end{array}$ & $\begin{array}{l}\text { Non } \\
\text { N(\%) }\end{array}$ \\
\hline Xerostomia & $87(43,5)$ & $16(8)$ \\
\hline $\begin{array}{l}\text { Periodontal disease } \\
\text { without pockets }\end{array}$ & $78(39,5)$ & $48(24)$ \\
\hline Tooth ache +deep caries & $63(31.5)$ & $48(29.8)$ \\
\hline Candidiasis & $59(29,5)$ & $5(2,5)$ \\
\hline Dental mobility & $141(70.5)$ & $28(14)$ \\
\hline Tooth discoloration & $4(0.5)$ & $8(4)$ \\
\hline Dental abscess & $31(15,5)$ & $3(1,5)$ \\
\hline Tobacco melanosis & $3(1,5)$ & $0(0,0)$ \\
\hline Pockets & $26(13)$ & $46(23)$ \\
\hline Leukoplakia & $13(7,5)$ & $0(0,0)$ \\
\hline Superficial caries & $11(5.5)$ & $72(44.7)$ \\
\hline No pathology & $109(54.5)$ & $0(0)$ \\
\hline Edentulousness & $108(54)$ & $48(28)$ \\
\hline Oral ulcer & $0(0)$ & $2(1.2)$ \\
\hline
\end{tabular}

\section{H. Treatment needs}

Smokers needed tooth extractions $56(36.8 \%)$ while nonsmokers needed more of restorations $24(12 \%)$ (Table 10$)$.

TABLE 10: TREATMENT NEEDS

\begin{tabular}{|l|c|c|}
\hline Treatment needs & $\begin{array}{c}\text { Smokers } \\
\text { N(\%) }\end{array}$ & $\begin{array}{c}\text { Non-smokers } \\
\text { N(\%) }\end{array}$ \\
\hline Scaling and polishing & $11(5.5)$ & $9(5.9)$ \\
\hline Extraction + protheses & $11(5.5)$ & $4(2.6)$ \\
\hline Simple extractions & $56(36.8)$ & $16(8.0)$ \\
\hline Restorations & $9(5.9)$ & $24(12.0)$ \\
\hline No treatment & $0(0)$ & $114(57)$ \\
\hline Total & $\mathbf{2 0 0 ( 1 0 0 )}$ & $\mathbf{2 0 0}(\mathbf{1 0 0})$ \\
\hline
\end{tabular}

\section{DISCUSSION}

\section{A. Demographics}

All age groups were represented in this study and was noticed that individuals of higher socioeconomic status smoked less than that the lower socioeconomic groups. Though people in this group form a smaller proportion of the population, they are also made up of the highly literate. Literacy is important in health promotion because the more literate an individual is, the easier it is for the individual to understand and have access to health information. Literacy has an important role to play in tobacco consumption and cessation as low literacy is associated with a variety of adverse health outcomes, including increased mortality, hospitalization, and in some cases poorer control of chronic health conditions [23]. A study carried out by steward and colleagues on tobacco cessation, suggested that lower health literacy may serve as an independent risk factor for smoking relapse among people of low-socio-economic status. The literacy rate of Cameroon is high $(71.3 \%)$ as compared to other African countries, the bulk of the smokers in the current study though literate, are of the low socio-economic groups as a result of unemployment or under-employment. This exposes these individuals to stress, alcoholism and subsequently smoking.
Irrespective of stringent government policies to reduce smoking, a large proportion of the population still smoke. The same reason is applicable to other low income countries especially in Africa where tobacco consumption is endemic. Besides, high taxes and the existence of anti-smoking regulations in western countries push the tobacco companies to settle in African countries on the pretext of reducing unemployment $[4,12]$. Our study was able to show that being literate does not necessarily mean you are health literate.

The current study showed that women consume tobacco less as compared to men. The world health organization Youths Global Tobacco Survey in Cameroon in 2012 [4] also estimated a higher male preponderance as compared to females amongst smokers. This may be attributed to the fact that males participate more on recreational outdoor activities in Cameroon like drinking which exposes them to more tobacco than females who cater for their families. In Cameroon some cultures forbids women from cigarette consumption and attaches a lot to stigmas to it.

The 15-45 years was most represented in our study, an age range made up of youth and the middle aged full of life that combine alcohol and tobacco as an episode of fun in their distractions. Alcohol has a synergistic effect on tobacco related pathologies like oral precancerous and cancerous lesions.

\section{B. Risk factors for oral diseases}

In the current study, lack of financial resources, inadequate visits to the dentist, the use of indigenous treatments were some of the risk factors related to some tobacco related diseases. More than half of the participants brushed inappropriately before meals. The frequency of inappropriate brushing was higher in smokers where three quarters do not brush after meals. This is a major risk factor for dental caries. This brushing was often carried out with the use plant stem, charcoal, the finger and water through the horizontal brushing method which further aggravate the oral hygiene condition of the participants evidenced by the high prevalence of dental caries amongst smokers, significantly higher than nonsmokers [mean, 4.4].

The frequencies of toothache and sensitivities in carious cavitations in smokers was lower compared to non-smokers reflected the absence of symptoms including pain. This can be due to the alteration of the dental nerve endings in the pulp and dental tubules by tobacco combustion heat or may be due to the therapeutic properties (healing, analgesic) of the plant Nicotinia tabacum [18].Low pain and dental sensitivities amongst the smokers are the reasons why these participants presented late with many retained roots and advanced dental caries with pulp involvements.

\section{Tobacco consumption}

More than half of the tobacco consumers take tobacco only and three quarters take alcohol in combination with alcohol. This demonstrates the strong nicotine dependence generated vis-à-vis the smoking tobacco.

Cases of poly drug use were observed amongst some participants who consumed tobacco in combination with Cannabis, Heroin and Cocaine. Tobacco and Tramadol was also observed to be consumed by $4 \%$ of the subjects. This is due to the euphoric effects generated by these substances addicts through the release of dopamine in the brain. This 
corresponds to a report by Benowitz (1996) who reported that regular tobacco smokers in the Swiss population also consume alcohol excessively [25]. The dose of harmful substances absorbed by the smoker depends to a large extent in smoking mode. In our study the main variables in cigarettes consumption described by Benowitz (1996) such as the number of puffs per cigarette, depth of inhalation, length of the remaining stub, and presence of a filter cigarette brand, the quantity and quality alcohol[25] were not taken into account during the identification of oral diseases.

Most smokers consumed more than 15 sticks a day which is most often combined with cannabis. This is due to the affordability of cigarette, and expansion of cannabis farming and sale in Cameroon. The majority of participantsin our study consumed 12.6 sticks of cigarettes per day which is higher than that of the Switzerland [7 cigarettes a day], a figure that is exceeded only by Spain, Greece, Cyprus, Romania and the Netherlands [6].

More than two thirds of the participantsin our study consumed Smokeless tobacco in the form of tobacco leaves placed in the form of tobacco pellets in the cheeks opposite the gums. This form of tobacco consumption has been reported in Cameroon and is assumed to be responsible for oral cancer or other precancerous lesions [19].

Though less than a quarter of the participantsin our study inhaled tobacco powder in the form of tobacco snuff, fewer studies have been carried out in Cameroon to demonstrate their impact on the orofacial region

\section{Oral pathologies}

Hyperpigmentation were found in the majority of smokers in localized areas of deposits and support points of the cigarette presenting in the form of black to grayish discolorations due to the deposition of tar on the oral mucosa of smokers. Similarly, Axell and Hedin (1982) and Hedin et al. (1993) demonstrated this type of melanosis in $21.5 \%$ of smokers, and the intensity of the pigment was related to the amount of tobacco consumed and consumption time [26-27].

Bad breath and tooth discoloration in the form of yellowish, brownish, grayish and blackish deposits were also observed in our study. Dental discolorations observed in our study are comparable to those of Saini et al. (2005) who demonstrated a higher frequency of dental discoloration in smokers of cigarettes and methamphetamine [28].Benowitz (1996) have demonstrated that the use of tobacco products is also an important factor halitosis in smokers [25].Since in nonsmokers halitosis could come from bacterial fermentation contained tartaric deposits, food and their general health states (diabetes, gastritis etc) it can be said that halitosis is not an objective clinical sign presented by smokers.

Xerostomia, poor oral hygiene visible by tartaric deposits and periodontal pockets were more pronounced present in the mouth of tobacco consumers where risk factors promoting the onset and rapid progression of caries. The painless nature of periodontal diseases in smokers could lead to their silent evolution of periodontal disease because their inflammatory response is attenuated in smokers.

Loss of epithelial attachment and tissue necrosis (lack of blood supply) were also observed in smokers as a result of high deposits of calculus leading to pathological bone resorption, leaving bare dentin, dentinal hypersensitivity sources and cervical caries.

The tooth mobility of various degrees and edentulousness were encountered in smoking subjects. This has been described to be due to the destruction of fibroblasts, collagen and ligament by salivary nicotine and also that smokers loose bone with age faster than non smokers [25]. Other contributing factors in our study to periodontitis, gingival recession, bone resorption, tooth mobility and the edentulous was the abundance of tartar (tobacco smokers) and the absence of dental prophylaxis. This confirms the hypothesis of Bergström et al. (1993) that smokers often have quite discrete signs of inflammation even with extensive tissue destruction primarily for previous sextants and palatal regions [25].

Two cases of palatal perforation have also been observed in the current study and was attributed to participantswho smoked cigars and pipe. Very few studies have shown that the effects of cigar and pipe and the mechanisms that cause significant bone lysis on the palate is not yet available. Gingival bleeding was less pronounced in smokers even when the majority presented with poor oral hygiene, such a difference does not seem to be as a result of an accumulation of plaque, but due to an inflammatory reaction caused by smoking. These might be due to vascular effects associated with a high content of carboxyhemoglobin from carbon monoxide, contributing to hypoxia and typical ischemic necrosis of acute necrotizing gingivitis [25]. Its complications generally result in periodontitis in $39 \%$ of cases; frequency which approximates the study Bergström et al (2000) have demonstrated the existence of $50 \%$ of periodontitis amongst Swiss smokers [15]. Though localized periodontitis were seen in fewer subjects, acute juvenile periodontitis was observed in younger participants below 10. Generalized chronic periodontitis were observed in the elderly while necrotic ulcerative periodontitis and necrotic ulcerative gingivitis were observed in some self-reported HIV-positive (6\%) subjects. The results of the current study on necrotic ulcerative periodontitis and necrotic ulcerative gingivitis are comparable to those of Sroussi et al. (2007) that demonstrated a relationship between HIV infection and periodontal disease[27].

In the present study, oral candidiasis regardless of the States General of the participants was raised in smokers and HIVpositive subjects. Holmstrup et al. (1983) also reported the presence of multifocal chronic candidiasis in tobacco smokers. It has been suggested that smoking uniquely or in combination with other factors is responsible for candidiasis and their recurrence after treatment [30].

In the current study, precancerous lesions like tobacco keratosis were typical in smokers. This was also associated to the general states of the participants and also presented in specific locations for example $7 \%$ of leukoplakia was located in the palate, $10 \%$, oral hairy leukoplakia were found in an HIV-positive subject. The prevalence of leukoplakia in the current study was lower than that reported by Agbor and Azodo (2013) who demonstrated the presence of $14.3 \%$ of leukoplakia in smokers population of adults to Fokoué[19]. Zheng et al (1990) in China, reported that up $17.43 \%$ of smoking-induced leukoplakia. They hinted that smoking 
could expose the participants by a $26 \%$ chance to develop into squamous cell carcinoma of the oral cavity if participants do not discontinue smoking. Mouth ulcers $(17 \%)$ were observed on the inner sides of the cheeks of the participants chewing tobacco. These ulcers could the existence can in its asymptomatic stage.

\section{E. Oral health treatment needs}

The oral health treatment needs were higher in smokers than in nonsmokers with smokers needing dental extractions and prosthesis than nonsmoker. The need of management of periodontal diseases was 4 times more in smokers than non smoker who will need scaling (mechanical removal of soft deposits and calcified dental), curettage and root planing. The presence of dental caries in these participants requires conservative care such indirect capping pulpectomy. However for those who cannot be preserved, particularly in smokers due to lack of significant coronary dilapidations, avulsion and prosthetic treatment are necessary to compensate for various disharmonies. Axelsson et al. (2004) who identified for the treatment of periodontal disease in smokers: elimination of soft and calcified dental deposits both supra-gingival and sub-gingival level, periodontal surgery in case of certain anatomical situations, and supportive therapy to life with periodontal cleaning. And essential additional measures for long-term treatment success are optimizing the home regular oral hygiene, smoking cessation and adequate psycho-social support process [32].

The current study showed a high frequency of oral diseases in tobacco smokers than non-smokers, with pathologies more present in males, low socioeconomic groups, the unemployed and people between 25-35 year old. Tobacco smokers presented with high caries lesions, high periodontal disease prevalence, oral mucosal lesions and precancerous lesions. Oral pathologies are frequently identified among smokers included melanoses, dental discolorations, halitosis, gingival recession, tooth mobility, gingivitis, periodontitis, precancerous lesions like lichen planus, leukoplakia, tobacco keratosis. Dental caries and periodontal abscess. The treatment needs identified included scaling ad polishing with oral hygiene instructions, periodontal surgery (curettage, gingivoplasties, avulsions and conservative dental care). We can therefore say that smoking is a modifiable risk factor for oral and periodontal health of our population in particular

\section{RECOMMENDATIONS}

The government should regulate the sale and use of tobacco products. The government should also intensify media advertising campaigns against smoking. The Ministry of Public Health and the national committee to fight against illicit drugs should include dentists in the anti-smoking campaign groups and also introduce their programs in school and academic outreach programs.

Clinicians should adopt the protocol of the anti-smoking therapy in dental practice and educate all risks groups about the risks of tobacco use. They should be actively involved in stop smoking campaigns and encourage smokers to the visit dentist regularly.

\section{Conflicts of interest}

The authors declare that they have no conflicting interests.

\section{Authors' contributions}

AMA,YFJJ participated in the concept, design, data collection, interpretation, analysis and writing of the manuscript.

SN participated in the concept and design, data analysis, interpretation and review of the manuscript.

\section{REFERENCES}

[1] J Owens . Oral health promotion for children with disabilities in the Republic of Ireland: independent qualitative evaluation of a multisectoral oral health promotion intervention for children with disabilities. Glob Health Promot. Issue 18 ,vol ,pp .69-71,2011

[2] M A Agbor, S Naidoo. Knowledge and practice of traditional healers in oral health in the Bui Division, Cameroon. $J$ Ethnobiol Ethnomed.,pp. 7: 6. ,2011.

[3] CF Ndiaye. Oral Health in the African Region: Progress and perspectives of the Regional Strategy. Afr J Oral Health ,vol 2, issue 2,pp. 2-9,2005.

[4] J Perriot, M Underner, L Doly-Kuchcik. Smoking: what are the health risks? Rev Prat.., vol 62, issue 3:pp. 333-6, 2012.

[5] MH Cherif .The tobacco problem in French-speaking Africa and regional perspectives of the French-speaking African tobacco observatory. Promot Educ.vol 4, pp. 45-7, 61, 2005.

[6] World Health Organization (WHO). Management of substance abuse. Lexicon of alcohol and drug terms published by the World Health Organization.

[Online].http://www.who.int/substance_abuse/terminology/who_lexic on/en/. (Accessed 10/11/2019).

[7] World Bank. Smoking prevalence, males (\% of adults). [Online]. http://data.worldbank.org/indicator/SH.PRV.SMOK.MA. (Accessed 10/11/2019).

[8] World Health Organization. WHO Report on the Global Tobacco Epidemic, 2011. Geneva: World Health Organization, 2011, [Online].

https://www.who.int/tobacco/global_report/2011/en/[(Accessed 10/11/2019).

[9] World Health Organization. WHO report on the global tobacco epidemic, 2013: Enforcing bans on tobacco advertising, promotion and sponsorship. Geneva, Switzerland: WHO. [Online]. http://www.who.int/tobacco/global_report/2013/en/.(Accessed 10/11/2019)

[10] Institut National de la Statistique et des études économiques (INSEE) (2010). Collège des médecins du Québec et Direction de la santé publique. La prévention et l'abandon du tabagisme, 1999. [Online]. https://www.inspq.qc.ca/pdf/publications/324AvisPreventionTabagismeJeunes.pdf.

[11] Preventing a tobacco epidemic in Africa. A Call for Effective Action to Support Health, Social, and Economic Development., [Online]. http://www.nationalacademies.org/asadi/Africa\%20Tobacco\%20Cont rol-FINAL.pdf

[12] World bank. http://data.worldbank.org/indicator/SH.PRV.SMOK.MA.

[Online].

[13] JM Albandar. Global risk factors and risk indicators for periodontal diseases. Periodontology,vol 29:pp. 177-206, 2000.

[14] OA Ayo-Yusuf, HW van den Borne, SP Reddy .Oral Health Promotion and Tobacco Use Prevention in South Africa: towards an integrated educational approach. PhD thesis, University of Pretoria. South Africa, 2008.

[15] J Bergström, S Eliasson, Haber, J Dock .A 10-year prospective study of tobacco smoking and periodontal health. J Periodontol., Vol 71 (8), pp. $1338-47,2000$.

[16] WC Gonsalves, AC Chi, BW Neville .Common oral lesions: Part II. Masses and neoplasia. Am Fam Physician., 75, pp. 509-12, 2007.

[17] ASK Sham, LKC heung, LJ Jin, EF Corbet.The effects of tobacco use on oral health. Hong Kong Med J .,vol 9,pp. 4,2003.

[18] CG Puscasu, ITM Gîrdea, AS Dumitriu, C Hanganu. Tobacco Smoking and Periodontal Conditions in an Adult Population from Constanta, Romania, OHDMBSC . vol 7 (3),pp. 1-7,2009.

[19] MA Agbor, CC Azodo, TSM Tefouet Smokeless tobacco use, tooth loss and oral health issues among adults in Cameroon. Afr Health Sci. Sep ,13(3),pp.785-90, 2013. 
[20] T Chandola , C Jenkinson. The new UK National Statistics SocioEconomic Classification (NS-SEC); investigating social class differences in self-reported health status. J Public Health Med., 22(2),pp.182-90,2000.

[21] J Ainamo, D Barmes, G Beagrie, T Cutress, J Martin, J Sardo-Infirri . Development of the World Health Organization (WHO) community periodontal index of treatment needs (CPITN). Int Dent J., vol 32(3),pp 281-9,1982.

[22] PD Miller .A classification of marginal tissue recession. Int $\mathrm{J}$ Periodontics Restorative Dent.5,pp 8-13,1985.

[23] MP Pignone, DA DeWalt .Literacy and Health Outcomes: Is Adherence the Missing Link? J Gen Intern Med.;vol 21(8), pp. 896897,2006 .

[24] DW Stewart, CE Adams, MA Cano, V Correa-Fernández, Y Li , AJ Waters, DW Wetter, JI Vidrine Associations between health literacy and established predictors of smoking cessation., vol 103,pp 7, May 16. ,2013.

[25] NL Benowitz, H Porchet, P Jacob, R Allardd. Pharmacokinetics, metabolism, and pharmacodynamics of nicotine. Nicotine psychopharmacology: molecular, cellular, and behavioural aspects. Oxford University Press. pp 1996, pp 112-157.

[26] Axell T, Hedin CA. Epidemiologic study of excessive oral melanin pigmentation with special reference to the influence of tobacco habits. Scand J Dent Res, vol 90(6), pp.434, 1982.

[27] CA Hedin, JJ Pinborg, T Axell. Disappearance of smoker's melnosis after reducing smoking. J Oral Pathol Med., vol 22: pp.228-30, (1993).

[28] T Saini, PC Edwards, NS Kimmes, LR Carroll, JW Shaner, FJ Doud .Etiology of xerostomia and dental caries among methamphetamine abusers. Oral Health Prev Dent.,3(3),pp,189-95,2005.

[29] HY Sroussi, D Villines, J Epstein, MC Alves, ME Alves .Oral lesions in HIV-positive dental patients. One more argument for tobacco smoking cessation. Oral Dis.,pp. 13:324,2007.

[30] P Holmstrup, M Bessermann .Clinical, therapeutic, and pathologic aspects of chronic multifocal candidiasis. Oral Surg Oral Med Oral Pathol; ,56, pp.388-95,1983.

[31] TZ Zheng, P Boyle , HF Hu, J Duan, PJ Jiang, DQ Ma , LP Shui, SR Niu , B MacMahon ,Tobacco smoking, alcohol consumption, and risk of oral cancer: a case-control study in Beijing, People's Republic of China. Cancer Causes Control., 1(2),pp. 173-9, 1990.

[32] P Axelsson, B Nyström, J Lindhe .The long-term effect of a plaque control program on tooth mortality, caries and periodontal disease in adults. Results after 30 years of maintenance. J Clin Periodontol., 31(9),pp.749-57,2004).

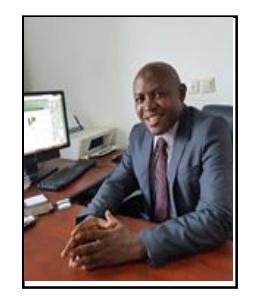

Ashu Michael Agbor is an Associate Professor in community oral health and Dean of the Université des Montagnes dental school, Bangangté -Cameroon. He studied dentistry at University of Benin dental school, Nigeria where he obtained his bachelor of dental surgery (BDS) in the year 2001. He is a holder of a post graduate diploma in community oral health at Radboard University, NigmegenHolland 2007. He obtained a masters in dental public health in 2009 at the University of the Western Cape in South Africa and also a PhD in Community oral health at the University of the Western Cape in 2015. He is a fellow and master of oral implantology from the ICOI (international congress of oral implantology since 2013 ) . He also a holder of a post doctorate certificate of competence in doctoral supervision for doctoral candidates in African Universities from Stellenbosch University since 2019 and also a fellow of the international college of dentist since 2011.

His a researcher in basic and clinical oral health. He has published widely on indigenous oral medicine, oral biology, dental education and community oral health. He has pioneer many community oral health programs in Cameroon.

Dr. Yougang Francine Josepha Jupkwo is a clinical assistant at the Université des Montagnes teaching hospital and working as a district dental surgeon in a district hospital in the Central Region of Cameroon. she obtained her DDS in dentistry from Université des Montagnes 2015. 